Part of Journal of Research of the National Bureau of Standards, Volume 26, June 1941

\title{
CRITICAL STUDY OF THE DETERMINATION OF CARBON MONOXIDE BY COMBUSTION OVER PLATINUM IN THE PRESENCE OF EXCESS OXYGEN
}

\author{
By Joseph R. Branham, Martin Shepherd, and Shuford Schuhmann
}

\section{ABSTRACT}

This is one of a series of papers reporting direct measurements of the fundamental accuracy of methods of gas analysis.

Carbon monoxide of known purity was analyzed by the slow-combustion method. The contraction after burning, the carbon dioxide produced, and the oxygen consumed were measured. Apparatus with and without rubber connections were used. The distinct effect of the amount of liquid water within the combustion pipette and burette was measured. Analyses were performed with all gases dry, as well as saturated with respect to water vapor. The stoichiometric relationship representing ideal physical and chemical conditions is $2 \mathrm{CO}+\mathrm{O}_{2} \rightarrow$ $2 \mathrm{CO}_{2}+\mathrm{TC}$ (where $\mathrm{TC}=$ total contraction after burning); the observed relationship, representing average laboratory practice by the customary method and with the usual apparatus, was $2 \mathrm{CO}+1.001 \mathrm{O}_{2} \rightarrow 1.986 \mathrm{CO}_{2}+1.014 \mathrm{TC}$. The purity of the carbon monoxide, expressed as percentage by volume, was known to be higher than 99.99. The purity determined by analysis varied from 99.13 to 101.74 , depending on the measurement selected for calculation. Best results were obtained by computing $\mathrm{CO}$ from $\mathrm{TC}+\mathrm{CO}_{2}$; the purity so indicated was $100.01 \pm 0.04$. The differences between the observed relationships and the stoichiometric ones were essentially accounted for experimentally and theoretically.

\section{CONTENTS}

Introduction Page

II. Carbon monoxide used for analysis

1. Preparation .

2. Purity _.

3. Storage and transfer

III. Analytical apparatus $\ldots \ldots$

IV. Analytical procedure _.

V. Series 1 (conventional apparatus and procedure)

VI. Series 2 and 3 (conventional apparatus, but with no rubber connections. Procedure same as in series 1. Water in combustion pipette and burette: series $2,0.5 \mathrm{ml}$; series $3,0.1 \mathrm{ml}$ ) $\ldots \ldots \ldots . . . . . .579$

1. Effect of liquid water in the combustion pipette

2. Effect of rubber connections _._.

VII. Series 4 (no water and no rubber connections-all gases measured dry)

VIII. Series 5 (no water; no rubber connections; air used for the combustion instead of oxyge $a$ ) _........

IX. Correction of analytical data for known errors

1. Corrections for loss of $\mathrm{CO}_{2}$ by solution $\ldots \ldots \ldots \ldots 5$

2. Corrections for deviation from ideality

X. Computation as an unknown 


\section{INTRODUCTION}

One of the principal and best methods employed for the determination of carbon monoxide is combustion over hot platinum in the presence of excess oxygen - the so-called slow combustion method. The reproducibility of this method has long been known, even though infrequently disclosed. The fundamental accuracy of the method has not been previously known. This accuracy was measured by the simple, direct procedure of preparing carbon monoxide of high purity, measuring its purity by a method far more sensitive and accurate than the analytical method to be studied, and then analyzing this known substance by the method under investigation to observe the deviation from known fact. In addition, an explanation of this deviation has been experimentally and theoretically worked out.

\section{CARBON MONOXIDE USED FOR ANALYSIS}

\section{PREPARATION}

The carbon monoxide for this investigation was prepared by the reaction of phosphoric acid with formic acid, and was purified by fractional distillation at low temperatures in a rectifying column.

The generator used is illustrated schematically in figure 1 . The various glass parts were fused directly together, or connected by ground glass joints sealed with a thermoplastic cement or a highvacuum lubricant. The parts comprising the generator are:

$A$, leveling bulb containing mercury, connected by rubber nitrometer tubing to $B$.

$B$, reservoir containing a small amount of formic acid over mercury.

$C$, drop counter.

$D$ and $E$, generating flasks containing 85 percent phosphoric acid.

$F$, condenser for excess water.

$G$, absorber filled with Ascarite.

$H$, condenser, with filter, immersed in liquid air.

$I, J$, and $K$, barometric mercury seals.

The stopcocks are numbered.

Since the reagents employed may be expected to yield dissolved air, and particularly nitrogen whose removal from carbon monoxide would be difficult if not impossible, the procedure was planned to remove dissolved gases prior to generating the carbon monoxide. The following steps were taken:

1. The apparatus to the left of cock 5 was evacuated through cock 4 to a pressure slightly above that of the vapor pressure of the formic acid.

2. The apparatus was filled to cock 3 with carbon dioxide through cock 1. This carbon dioxide was taken from a commercial cylinder which was about half full. Analysis of large samples of the gas indicated freedom from any significant amount of air.

3 . The apparatus was evacuated and refilled with carbon dioxide four times.

4. After the fourth filling, carbon dioxide was passed for 48 hours through the apparatus to the outside, through the lower outlet of cock 3. The inlets of $D$ and $E$ terminated in bubbler tips of the BranhamSperling type [1], ${ }^{1}$ which insured intimate contact between the carbon

\footnotetext{
1 Figures in brackets indicate the literature references at the end of this paper.
} 
dioxide and acid, and further displacement of dissolved gases not already removed by the previous steps.

5. The phosphoric acid in both $D$ and $E$ was heated to $150^{\circ} \mathrm{C}$, and then formic acid was admitted dropwise to $D$. The rate of flow of formic acid was adjusted by admitting mercury from $A$ through the control cock, 6 . The generation of carbon monoxide was immediate, and this gas was at first allowed to escape through the barometric seals, and then to fill the absorber, $G$, and escape through the seal, $K$.

6. While the reaction thus proceeded, the apparatus was thrice evacuated and refilled with the generated gas. Thereafter, the gas produced was allowed to escape through seal, $K$, for 2 hours.

7. The apparatus to the right of cock 5, of which only a condenser is shown [2], was the one used in this laboratory to purify gases by

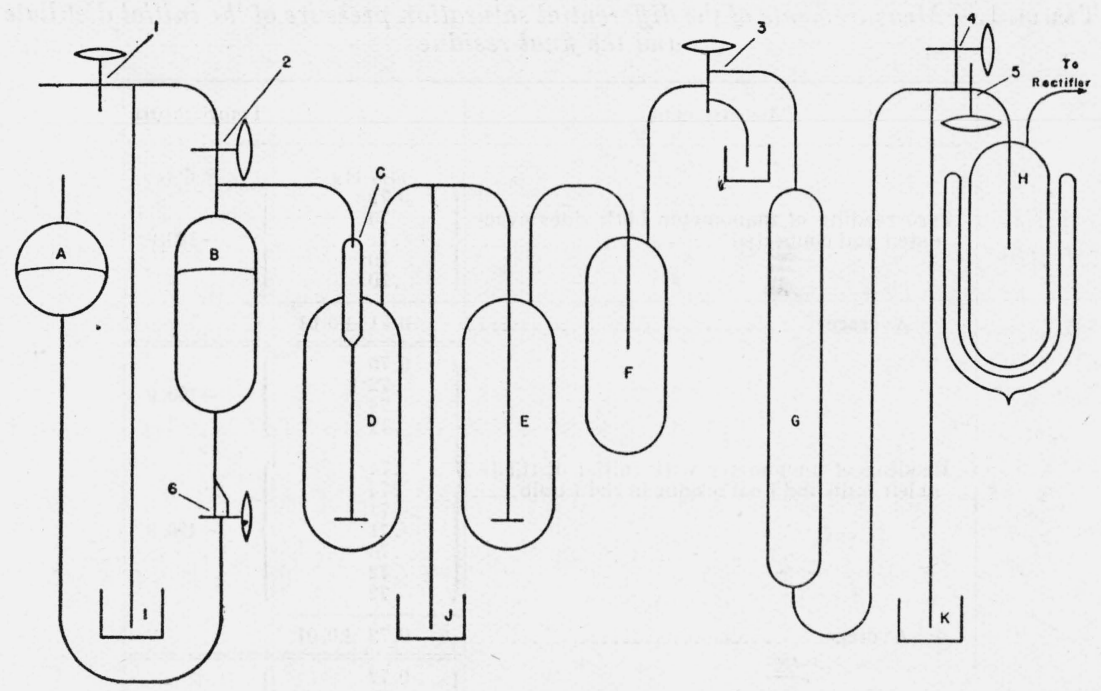

FigURE 1.-Flow diagram of apparatus for generating carbon monoxide.

fractional distillation, and to determine purity by measuring the difference between the saturation pressures of an initial condensate and a final residue obtained by distillation. This apparatus was evacuated to maintain a pressure of $<0.0001 \mathrm{~mm} \mathrm{Hg}$.

8. After the above operations were concluded, the carbon monoxide was passed through the condenser, $H$, and from there to evacuated receivers. The rate of flow into these receivers was adjusted so that the pressure in $H$ kept the carbon monoxide at the point of incipient liquefaction. About 70 liters of gas was collected, during which time several milliliters of condensate was deposited in $H$. This step would partially remove higher boiling gases if any such were present and had escaped the Ascarite.

9. The gas collected in the receivers was then liquefied in the boiling pot of a rectifying column of the purification apparatus, and distilled at the rate of approximately 6 liters (gas) per hour under equilibrium conditions at $-190^{\circ} \mathrm{C}$. The first 25 liters of gaseous distillate was discarded, the apparatus was then thoroughly evacuated up to the 
rectifier outlet, and the next 20 liters of gaseous distillate was collected for examination, the balance being discarded. (See methods described [2].)

\section{PURITY}

The purity of the distillate so obtained was measured by the method of differential saturation pressures previously reported [3]. In this test, the saturation pressure of an initial distillate was compared with that of a final residue, with no middle fraction included. The distillate and residue were obtained by rectification rather than by simple isothermal distillation. These conditions impose the severest test for purity of which this sensitive method is capable. The measurements are given in table 1.

TABLE 1.-Measurements of the differential saturation pressure of the initial distillate and the final residue

\begin{tabular}{|c|c|c|}
\hline Measurement & $\Delta p$ & Temperature \\
\hline $\begin{array}{l}\text { Zero reading of manometer both sides evac- } \\
\text { uated and connected. }\end{array}$ & $\begin{array}{l}m m \mathrm{Hg} \\
0.72 \\
.70 \\
.71 \\
.70 \\
.70\end{array}$ & $\begin{array}{l}{ }^{\circ} C \\
-190.9\end{array}$ \\
\hline \multirow[t]{2}{*}{ A verage.. } & $0.71 \pm 0.01$ & \\
\hline & $\begin{array}{l}0.70 \\
.72 \\
.74 \\
.72\end{array}$ & -190.9 \\
\hline $\begin{array}{l}\text { Reading of manometer with initial distillate } \\
\text { in left bulb and final residue in right bulb.... }\end{array}$ & $\begin{array}{l}.74 \\
.73 \\
.71 \\
.71 \\
.70 \\
.72 \\
.72\end{array}$ & \multirow[t]{2}{*}{-190.8} \\
\hline A verage.... & $0.72 \pm 0.01$ & \\
\hline Zero reading of manometer repeated & $\begin{array}{l}0.72 \\
.72 \\
.72 \\
.72\end{array}$ & \multirow[t]{2}{*}{-190.6} \\
\hline Average.... & 0.72 & \\
\hline
\end{tabular}

It will be seen that no significant difference exists between the saturation pressures of the initial distillate and the final residue. Within the limit of sensitivity of the test, the carbon monoxide used in this investigation was pure.

The sensitivity of the test for this particular case may be estimated from the formula

$$
\Delta x_{B}=\frac{\Delta_{p}}{p_{B}{ }^{\circ}-p_{A}{ }^{\circ}},
$$

where $\Delta x_{B}$ is the difference in purity between the initial distillate and final residue, expressed as the mole fraction of the impurity $B ; p_{B}{ }^{\circ}$ and $p_{A}{ }^{\circ}$ are, respectively, the saturation pressures of the impurity, $B$, in its pure state and the approximately pure substance, A, in its pure state, at the temperature of the test; and $\Delta p$ is the differential saturation pressure measured by the manometer. The lower-boiling impurities to be suspected are nitrogen or hydrogen; the higher-boiling 
impurities are methane or higher-boiling hydrocarbons. A difference of $0.01 \mathrm{~mm}$ in saturation pressure would result from any one of the following differences between the impurity in the initial distillate and that in the final residue:

1. 0.00002 mole fraction of nitrogen.

2. Very much less than 0.00002 mole fraction of hydrogen.

3. 0.00001 mole fraction of methane.

4. Very much less than 0.00001 mole fraction of ethane or heavier hydrocarbons, carbon dioxide, and other higher-boiling gases.

Actually, while the measurements given do not disclose the fact, the manometer cannot ordinarily be trusted to $\pm 0.01 \mathrm{~mm}$, but 0.03 $\mathrm{mm}$ is a conservative figure. This would indicate that no single impurity exceeded 0.00005 mole fraction in the carbon monoxide used and insures satisfactory purity of this gas.

\section{STORAGE AND TRANSFER}

The sample was transferred by liquefaction and subsequent vaporization to a carefully prepared container sealed to the purification apparatus. (For details of method, see [2].) Here it was stored over mercury. This container was sealed directly to the burette of the analytical apparatus, and means provided for alternately evacuating and flushing the sampling line with mercury and with the sample itself. Thus the identity of the sample was preserved throughout the analyses.

\section{ANALYTICAL APPARATUS}

The carbon monoxide was analyzed with the apparatus regularly used in this laboratory for this type of work [4]. Part of the work was done with a modified form of this apparatus, which included small tubes for desiccants and solid reagents [5]. Many of the analyses were made with all rubber connections eliminated from the apparatus. Two series were performed with a dry compensator and burette, all the gases being dried over $\mathrm{P}_{2} \mathrm{O}_{5}$ before measurement.

\section{ANALYTICAL PROCEDURE}

Analyses were carefully made according to the general procedures previously set forth in considerable detail [4]. Five separate groups of analyses were performed, and in some cases the general procedures referred to were modified to fit the particular need of the group. Since these analyses will be discussed separately, any modification of general procedure will be noted with the discussion of the series involved. In general, the procedure was as follows:

1. About $60 \mathrm{ml}$ of $\mathrm{N}_{2}$ was measured and stored over the $\mathrm{KOH}$ or pyrogallol solution.

2. About $60 \mathrm{ml}$ of oxygen was measured and stored in the combustion pipette.

3. Very close to $60 \mathrm{ml}$ of $\mathrm{CO}$ was measured and transferred slowly (15 to $20 \mathrm{~min}$ ) over the heated spiral of the combustion pipette. After four additional passes over the wire (15 to $20 \mathrm{~min}$ additional), the contraction was measured.

4. The $\mathrm{CO}_{2}$ was removed and with the usual dilution passed into the combustion pipette to regain the small amount of this gas left in this portion of the distributor. 
5. The excess $\mathrm{O}_{2}$ was removed and with dilution passed into the $\mathrm{KOH}$ and combustion pipettes.

Of the various reagents we have used to determine $\mathrm{CO}_{2}$ in the products of combustion, a saturated aqueous solution of $\mathrm{KOH}$ was chosen for this work. This reagent has given a good account of itself with respect to the low solubility of inert gases [6].

\section{SERIES 1}

(Conventional apparatus and procedure)

This series of analyses is perhaps the most noteworthy, though not the most interesting, since, from the practical viewpoint, it offers a general measure of the fundamental accuracy of the determination as ordinarily performed in the laboratory with modern apparatus and with reasonable care. The procedures employed have been previously discussed [6] and no detail need be repeated here except to state that the apparatus employed the customary rubber connections, except for the introduction of the sample; a total of $0.1 \mathrm{ml}$ of water in the burette and combustion pipette was used for saturating the gases measured; and the proportion of $\mathrm{CO}_{2}$ in the products of combustion was 0.66 of the total.

The analytical data for this series are given in table 2 under series 1 . A brief explanation of this table may be given with reference to the column numbers. Columns 1, 2, and 3 give, respectively, the milliliters of total contraction (TC), carbon dioxide produced $\left(\mathrm{CO}_{2}\right)$, and oxygen consumed $\left(\mathrm{O}_{2}\right)$. These have all been reduced to the common basis of a sample of $60 \mathrm{ml}$ of carbon monoxide. Thus all corresponding measurements for all analyses are directly comparable. Since these data are expressed in milliliters, the unit used in making the actual observations, any deviations greater than the expected uncertainty in the volumetric measurement $( \pm 0.03)$ may be seen at a glance. Column 4 notes the gain or loss of $\mathrm{N}_{2}$ during each analysis. Columns 5, 6, and 7 give, respectively, the percentages of $\mathrm{CO}$ computed from $\mathrm{TC}, \mathrm{CO}_{2}$, and $\mathrm{O}_{2}$. Column 8 gives the percentage of $\mathrm{CO}$ computed from $\mathrm{TC}+\mathrm{CO}_{2}$, the most reliable combination we have found in dealing with the combustion of carbon-bearing gases. This combination automatically eliminates errors caused by loss of $\mathrm{CO}_{2}$ in water, rubber, etc., and eliminates the effect of the deviation of $\mathrm{CO}_{2}$ from ideality.

TABLE 2.-Analytical data

\begin{tabular}{c|c|c|c|c|c|c|c}
\hline 1 & 2 & 3 & 4 & 5 & 6 & 7 & 8 \\
\hline $\mathrm{TC}$ & $\mathrm{CO}_{2}$ & $\mathrm{O}_{3}$ & $\mathrm{~N}_{2}$ & $2 \mathrm{TC} / \mathrm{S}$ & $\mathrm{CO}_{2} / \mathrm{S}$ & $2 \mathrm{O}_{2} / \mathrm{S}$ & $\frac{3 / 2\left(\mathrm{TC}+\mathrm{CO}_{2}\right)}{\mathrm{S}}$ \\
\hline
\end{tabular}

Series 1. Connections made with rubber tubing. $66 \%$ of $\mathrm{CO}_{2}$ in products. $0.1 \mathrm{ml}$ of $\mathrm{H}_{2} \mathrm{O}$ present

\begin{tabular}{|c|c|c|c|c|c|c|c|}
\hline $\begin{array}{r} \\
30.40 \\
30.35 \\
30.39 \\
30.39 \\
30.49\end{array}$ & $\begin{array}{l}m l \\
59.62 \\
59.64 \\
59.56 \\
59.57 \\
59.51\end{array}$ & $\begin{array}{l}m l \\
30.29 \\
29.99 \\
30.01 \\
30.07 \\
30.02\end{array}$ & $\begin{array}{l}m l \\
+0.25 \\
-.01 \\
+.04 \\
+.09 \\
+.01\end{array}$ & $\begin{array}{c}\% \text { CO } \\
101.33 \\
101.17 \\
101.30 \\
101.30 \\
101.63\end{array}$ & $\begin{array}{l}\text { \% CO } \\
99.37 \\
99.40 \\
99.27 \\
99.28 \\
99.18\end{array}$ & $\begin{array}{c}\% \mathrm{CO} \\
100.97 \\
99.97 \\
100.03 \\
100.23 \\
100.07\end{array}$ & $\begin{array}{r}\% \mathrm{CO} \\
100.02 \\
99.99 \\
99.96 \\
99.97 \\
100.00\end{array}$ \\
\hline $\begin{array}{l}30.48 \\
30.48 \\
30.47 \\
30.44 \\
30.43\end{array}$ & $\begin{array}{l}59.51 \\
59.55 \\
59.52 \\
59.61 \\
59.64\end{array}$ & $\begin{array}{l}30.06 \\
29.96 \\
30.08 \\
30.06 \\
30.07\end{array}$ & $\begin{array}{r}+.06 \\
+.07 \\
+.08 \\
+.01 \\
.00\end{array}$ & $\begin{array}{l}101.60 \\
101.60 \\
101.57 \\
101.47 \\
101.43\end{array}$ & $\begin{array}{l}99.18 \\
99.25 \\
99.20 \\
99.35 \\
99.40\end{array}$ & $\begin{array}{r}100.20 \\
99.87 \\
100.27 \\
100.20 \\
100.23\end{array}$ & $\begin{array}{r}99.99 \\
100.03 \\
99.99 \\
100.04 \\
100.08\end{array}$ \\
\hline
\end{tabular}


TABLE 2.-Analytical data-Continued

\begin{tabular}{c|c|c|c|c|c|c|c}
\hline 1 & 2 & 3 & 4 & 5 & 6 & 7 & 8 \\
\cline { 1 - 3 } & $\mathrm{CO}_{2}$ & $\mathrm{O}_{2}$ & $\mathrm{~N}_{2}$ & $2 \mathrm{TC} / \mathrm{S}$ & $\mathrm{CO}_{2} / \mathrm{S}$ & $2 \mathrm{O}_{2} / \mathrm{S}$ & $\frac{3 / 2\left(\mathrm{TC}+\mathrm{CO}_{2}\right)}{\mathrm{TC}}$ \\
\hline
\end{tabular}

Series 1. Connections made with rubber tubing. $66 \%$ of $\mathrm{CO}_{2}$ in products. $0.1 \mathrm{ml}$ of $\mathrm{H}_{2} \mathrm{O}$ present-Con.

\begin{tabular}{|c|c|c|c|c|c|c|c|c|}
\hline & $\begin{array}{r}m l \\
30.39 \\
30.48 \\
30.40 \\
30.39 \\
30.37\end{array}$ & $\begin{array}{l}m l \\
59.64 \\
59.63 \\
59.55 \\
59.58 \\
59.63\end{array}$ & $\begin{array}{l}m l \\
29.99 \\
30.12 \\
29.90 \\
30.02 \\
29.96\end{array}$ & $\begin{array}{r}m l \\
-.05 \\
.00 \\
-.06 \\
+.03 \\
-.05\end{array}$ & $\begin{array}{l}\% \mathrm{CO} \\
101.30 \\
101.60 \\
101.33 \\
101.30 \\
101.23\end{array}$ & $\begin{array}{c}\% \mathrm{CO} \\
99.40 \\
99.38 \\
99.25 \\
99.30 \\
99.38\end{array}$ & $\begin{array}{l}\text { \% CO } \\
99.97 \\
100.40 \\
99.67 \\
100.07 \\
99.87\end{array}$ & $\begin{array}{r}\% \mathrm{CO} \\
100.03 \\
100.12 \\
99.94 \\
99.98 \\
100.00\end{array}$ \\
\hline & $\begin{array}{l}30.39 \\
30.36 \\
30.35 \\
30.42\end{array}$ & $\begin{array}{l}59.55 \\
59.65 \\
59.65 \\
59.66\end{array}$ & $\begin{array}{l}30.08 \\
30.01 \\
29.98 \\
29.90\end{array}$ & $\begin{array}{r}+.13 \\
.00 \\
-.03 \\
-.18\end{array}$ & $\begin{array}{l}101.30 \\
101.20 \\
101.17 \\
101.40\end{array}$ & $\begin{array}{l}99.25 \\
99.42 \\
99.42 \\
99.43\end{array}$ & $\begin{array}{r}100.27 \\
100.03 \\
99.93 \\
99.67\end{array}$ & $\begin{array}{r}99.93 \\
100.01 \\
100.00 \\
100.09\end{array}$ \\
\hline Avg. & $30.41 \pm .04$ & $59.59 \pm .05$ & $30.03 \pm .06$ & $+.01 \pm .06$ & 101. $38 \pm .13$ & $99.32 \pm .08$ & $100.10 \pm .21$ & $100.01 \pm .04$ \\
\hline
\end{tabular}

Series 2. No rubber connections. $66 \%$ of $\mathrm{CO}_{2}$ in products. $0.5 \mathrm{ml}$ of $\mathrm{H}_{2} \mathrm{O}$ present

\begin{tabular}{|c|c|c|c|c|c|c|c|c|}
\hline & $\begin{array}{l}30.57 \\
30.53 \\
30.52 \\
30.50 \\
30.56\end{array}$ & $\begin{array}{l}59.49 \\
59.42 \\
59.50 \\
59.55 \\
59.41\end{array}$ & $\begin{array}{l}30.14 \\
29.99 \\
30.13 \\
30.08 \\
30.09\end{array}$ & $\begin{array}{r}+0.08 \\
+.02 \\
+.10 \\
+.02 \\
+.11\end{array}$ & $\begin{array}{l}101.90 \\
101.77 \\
101.73 \\
101.67 \\
101.87\end{array}$ & $\begin{array}{l}99.15 \\
99.03 \\
99.17 \\
99.25 \\
99.02\end{array}$ & $\begin{array}{r}100.47 \\
99.97 \\
100.43 \\
100.27 \\
100.30\end{array}$ & $\begin{array}{r}100.07 \\
99.96 \\
100.02 \\
100.06 \\
99.97\end{array}$ \\
\hline & $\begin{array}{l}30.46 \\
30.52 \\
30.53 \\
30.52\end{array}$ & $\begin{array}{l}59.52 \\
59.52 \\
59.40 \\
59.51\end{array}$ & $\begin{array}{l}29.99 \\
30.12 \\
29.90 \\
30.04\end{array}$ & $\begin{array}{r}.00 \\
+.08 \\
-.03 \\
.00\end{array}$ & $\begin{array}{l}101.53 \\
101.73 \\
101.77 \\
101.73\end{array}$ & $\begin{array}{l}99.20 \\
99.20 \\
99.00 \\
99.18\end{array}$ & $\begin{array}{r}99.97 \\
100.40 \\
99.67 \\
100.13\end{array}$ & $\begin{array}{r}99.98 \\
100.04 \\
99.92 \\
100.03\end{array}$ \\
\hline Avg. & $30.52 \pm .02$ & $59.48 \pm .05$ & $30.05 \pm .07$ & $+.04 \pm .04$ & $101.74 \pm .07$ & $99.13 \pm .08$ & $100.17 \pm .22$ & $100.01 \pm .04$ \\
\hline
\end{tabular}

Series 3. No rubber connections. $66 \%$ of $\mathrm{CO}_{3}$ in products. $0.1 \mathrm{ml}$ of $\mathrm{H}_{2} \mathrm{O}$ present

\begin{tabular}{r|r|r|r|r|r|r|r}
\hline 30.35 & 59.62 & 29.96 & -0.02 & 101.17 & 99.37 & 99.87 & 99.97 \\
30.34 & 59.66 & 29.99 & -.02 & 101.13 & 99.43 & 99.97 \\
30.36 & 59.66 & 30.05 & +.02 & 101.20 & 99.43 & 100.17 & 17 \\
30.36 & 59.72 & 30.05 & -.03 & 101.20 & 99.53 & 100.17 & 99.83 \\
30.25 & 59.74 & 29.95 & -.04 & 100.83 & 99.57 & 100.02 \\
100.08 \\
99.98 \\
30.33 & 59.66 & 30.04 & +.04 & 101.10 & 99.43 & 100.13 & 99.99 \\
30.29 & 59.75 & 30.03 & -.01 & 100.97 & 99.58 & 100.10 & 100.04 \\
Avg. $30.33 \pm .03$ & $59.69 \pm .04$ & $30.01 \pm .04$ & $-.01 \pm .02$ & $101.09 \pm .10$ & $99.48 \pm .07$ & $100.03 \pm .12$ & $100.01 \pm .03$ \\
\hline
\end{tabular}

Series 4. No rubber connections. $66 \%$ of $\mathrm{CO}_{2}$ in products. $\mathrm{No}_{2} \mathrm{O}$ present

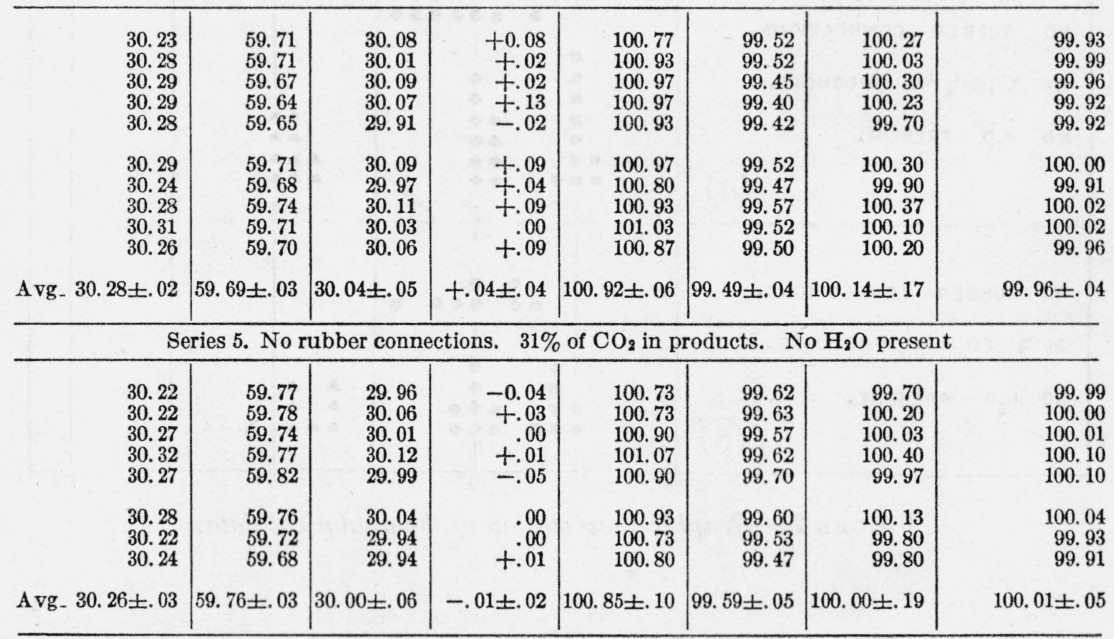


CALCULATED PERCENT CARBON MONOXIDE

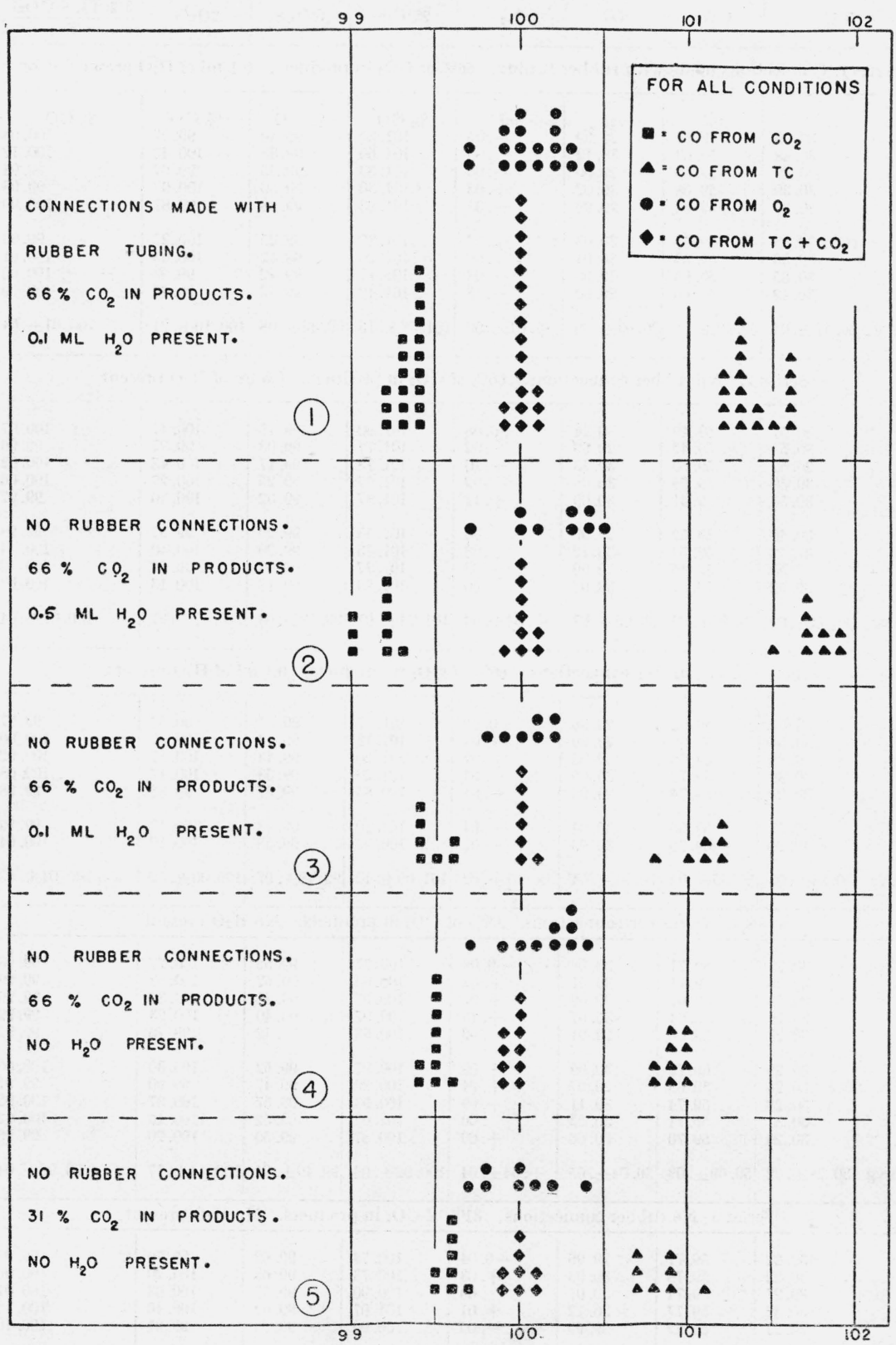

Figure 2.-Graphic presentation of the analytical data. 
The data are presented graphically in figure 2, which is a frequency plot. Here the points represent percentages by volume of $\mathrm{CO}$. The squares are values computed from the $\mathrm{CO}_{2}$ produced upon combustion, the triangles are computed from the total contraction after burning, the circles are computed from the oxygen consumed, and the diamonds are computed from the more reliable combination of contraction (TC) $+\mathrm{CO}_{2}$ produced. The values in table 2 have been rounded off to the nearest 0.1 percent in this graph.

The picture is so obvious when thus presented that discussion seems gratuitous. Again there is the usual story to be expected from a carbon-bearing gas. Carbon monoxide is too high by 1.4 percent when computed from TC, too low by 0.7 percent when computed from $\mathrm{CO}_{2}$, too high by about 0.1 percent when computed from $\mathrm{O}_{2}$, and so nearly correct when computed from $\mathrm{TC}+\mathrm{CO}_{2}$ that the limit of accuracy of the volumetric measurement will suffice to explain whatever deviation from the known composition remains. The accuracy of the analysis thus has a direct measure. The reproducibility is equally well shown at a glance. Reproducibility (expressed as average deviation from the mean) for the determinations of $\mathrm{TC}$ and $\mathrm{CO}_{2}$ was about \pm 0.1 percent for each of the series; the total spread was 0.5 and 0.3 percent, respectively. Reproducibility was not so good when computed from $\mathrm{O}_{2}$, being \pm 0.2 percent, with a spread of 1.3 percent. The results computed from $\mathrm{TC}+\mathrm{CO}_{2}$ are remarkably consistent. Indeed, for the determination of the purity of a single carbon-bearing gas in the absence of other combustible gases, the best volumetric combustion procedure would be the removal of $\mathrm{CO}_{2}$ during the combustion, and the single measurement of the combined TC and $\mathrm{CO}_{2}$. Unfortunately, this procedure can rarely be employed.

\section{SERIES 2 AND 3}

(Conventional apparatus, but with no rubber connections. Procedure same as in series 1. Water in combustion pipette and burette: series $2,0.5 \mathrm{ml}$; series $3,0.1 \mathrm{ml})$

\section{EFFECT OF LIQUID WATER IN THE COMBUSTION PIPETTE}

The amount of water within the burette and combustion pipette is one factor determining the accuracy of the analysis. This has been discussed before [7] but inadequately, and may be briefly reconsidered. It is necessary, of course, to keep some water within the burette if all the gas volumes are to be completely saturated and thus made comparable on this basis. (This is general practice, since dry analyses have been considered too difficult.) The amount of water used by different operators varies somewhat, but the best technique calls for a film of water on the burette walls, with no excess to obscure the mercury meniscus. If this condition is maintained, the total amount of water is, curiously enough, practically constant. If, however, free or combined hydrogen is burned, water is supplied to the combustion pipette, and accumulates therein if not regularly expelled. General practice has been to remove this condensate when it becomes troublesome-and this means that the amount of water may vary considerably from time to time - certainly over the range 0.1 to $1 \mathrm{ml}$, depending on the whim and preoccupation of the manipulator. 
The physical picture with respect to this water is clear. When the gas is first burned and the condensate forms, it dissolves $\mathrm{CO}_{2}$ from the products of combustion. The contraction measured after burning is correspondingly too high and the $\mathrm{CO}_{2}$ equally too low. Next, after removal of the greater part of the $\mathrm{CO}_{2}$ by absorption in $\mathrm{KOH}$ solution, the residue is passed into the combustion pipette to regain the small amount of this gas that has been left in the distributor connections; and at this moment the water within the combustion pipette may liberate the dissolved $\mathrm{CO}_{2}$ which is, of course, absorbed during the final passages into the $\mathrm{KOH}$ solution. This leaves the water within the combustion pipette free to dissolve more $\mathrm{CO}_{2}$ during the next combustion, a point previously ignored. If the water then accumulates, the amount of $\mathrm{CO}_{2}$ dissolved will increase with each succeeding combustion.

This was demonstrated experimentally by introducing a known amount of water into the combustion pipette and alternately passing $\mathrm{CO}_{2}$ and $\mathrm{N}_{2}$ into it, measuring the alternate decrease and increase of volumes corresponding to the absorption and liberation of the $\mathrm{CO}_{2}$. The amounts so retained and liberated corresponded with the known data for solubility under the experimental conditions. Absorption and desorption were rapid and apparently complete, since one passage of the gas (duration about $20 \mathrm{sec}$ ) was sufficient to give approximate equilibrium.

The effect upon the actual analysis is demonstrated experimentally in series 2 and 3 . During series 2 , a total of $0.5 \mathrm{ml}$ of water was kept within the combustion pipette and burette. This amount was reduced to $0.1 \mathrm{ml}$ during series 3 . A comparison of the data shows that the expected effect was observed. The data are given in table 2. A difference of $0.21 \mathrm{ml}$ of $\mathrm{CO}_{2}$ produced is noted, with a corresponding difference of $0.19 \mathrm{ml}$ in TC. This difference agrees with the value computed from the solubility of $\mathrm{CO}_{2}$ in water at its existing partial pressure and the average temperature of the analyses: $(0.4 \times 0.8 \times$ $0.66=0.21 \mathrm{ml}$, where 0.4 is the difference in milliliters of the amount of water, 0.8 is the solubility factor, and 0.66 the partial pressure of $\mathrm{CO}_{2}$ ).

The shift in values is easily seen in figure 2 . When the larger amount of water was present, the percentages computed from $\mathrm{CO}_{2}$ and from TC are pushed farther aside from the known fact; when the smaller amount of water was used, the corresponding values are drawn in closer to the 100-percent axis. The differences between the two series are about 0.6 percent of $\mathrm{CO}$ computed from $\mathrm{TC}$ and 0.3 percent computed from $\mathrm{CO}_{2}$. The values computed from $\mathrm{TC}+\mathrm{CO}_{2}$ are not significantly changed. The data indicate the necessity for modification of technique with respect to water accumulating in the combustion pipette. Considering the average temperature, the partial pressure of $\mathrm{CO}_{2}$ in products of combustion, and its solubility in water, the water should be limited to $0.1 \mathrm{ml}$.

\section{EFFECT OF RUBBER CONNECTIONS}

Before proceeding to the next series of analyses, series 1 should be compared with series 3 . The water during each series was $0.1 \mathrm{ml}$. Other conditions were comparable, except that the rubber connections used in series 1 were replaced with fused glass or cemented connections 
in series 3. The loss of $\mathrm{CO}_{2}$ through the rubber connections, an error previously discussed [8], is apparent when these analytical data are examined. Series 1 gives a higher value of $\mathrm{CO}$ from TC, and a lower one from $\mathrm{CO}_{2}$, than does series 3 . These differences amount to 0.3 and 0.2 percent, respectively, and correspond to a loss of $0.1 \mathrm{ml}$ of $\mathrm{CO}_{2}$ in the rubber-rather more than previous independent measurements would indicate, and probably more than is actually lost.

\section{SERIES 4}

(No water and no rubber connections-all gases measured dry)

In many respects series 4 is the most interesting group of analyses performed during this work. The procedure was novel in that all gases were measured dry instead of saturated with water vapor. Thus the loss of $\mathrm{CO}_{2}$ by solution in water was eliminated entirely. The apparatus had no rubber connections. The desiccant used was $\mathrm{P}_{2} \mathrm{O}_{5}$, small amounts of which were put on glass wool in tubes used to dry both the sample and the oxygen before they entered the burette, as well as all gases returned from reagents or the combustion pipette. Such an apparatus and the requisite procedures for using the dry burette and compensator have been described [5]. A review of this work will reveal most encouraging volumetric behavior in spite of the natural expectation that water vapor yielded from glass walls might continually interfere. Aside from the modification of apparatus and the drying of the gases, the analytical procedure was the same as for previous analyses.

The data show some decrease in the $\mathrm{CO}$ computed from the TC measured in this series, which was to be expected. However, contrary to expectation, there was no significant increase in the value derived from $\mathrm{CO}_{2}$. There was no decrease in the $\mathrm{CO}$ calculated from the measurement of excess $\mathrm{O}_{2}$.

During these analyses a curious thing was observed. The dry combustion pipette quickly collected what appeared to be considerable amounts of a grayish-black powder. It is true that this pipette never remains entirely clean, since iridium is deposited from the heated spiral, and mercury slowly fouls, even when transferred through the best grade of sulfur-free rubber tubing. But the fouling of the dry pipette appeared to be unmistakably worse and occurred in considerably less time than had ever been observed with the wet pipette. It is, of course, entirely possible that similar amounts of this substance are formed in the wet pipette, but are not obvious because a fluffy powder may be reduced in volume by the water, and be carried down the walls of the pipette with the moist mercury, gradually forming the dirty rings which are noticeable in the lower portions of the wet pipette.

These dry analyses presented further curious second-order effects. After the combustion, the gas was returned directly from the pipette for measurement. Thereafter, the gas was returned through the $\mathrm{P}_{2} \mathrm{O}_{5}$ to the pipette, and then back to the burette through the same desiccant. The second gas volume was usually less than the first by small amounts -0.02 to $0.05 \mathrm{ml}$. In computing the analysis, the second or the "dry" volume was taken. It is entirely possible that small amounts of water vapor were released from the heated wire and glass dome of the pipette, or crept up through the rubber tubing 
connected to the bottom of the pipette. This explanation most nearly fits the physical picture involved. We were unable to measure any adsorption of $\mathrm{CO}_{2}$ on the $\mathrm{P}_{2} \mathrm{O}_{5}$ during a set of control experiments designed to check this possible explanation.

Another puzzle developed during a second set of control experiments. Nitrogen, oxygen, or air could be repeatedly passed between the dry pipette and burette, either through the $\mathrm{P}_{2} \mathrm{O}_{5}$ or with this tube bypassed, with no significant change of volume. However, when the wire was heated, a small expansion was observed when nitrogen was passed into the pipette, and a small contraction was observed when oxygen (or air) was passed over the hot wire. The wet pipette gave no such effect with either gas. Extremely rigorous tests for leaks were made concurrently with these experiments, which, it will be remembered, were conducted in an apparatus without rubber connections. These expansions and contractions were of the order of magnitude of 0.05 to $0.1 \mathrm{ml}$ when the two gases were exposed to the hot wire for periods of one-half to 1 hour. There was also evidence of the formation of an acid gas when either expansion or contraction was observed. Of the many explanations which occurred, none seemed satisfactory.

Whatever the cause of the small contraction observed when $\mathrm{O}_{2}$ or air was passed over the heated spiral of the dry combustion pipette, its occurrence might explain an increased $\mathrm{TC}$ and $\mathrm{O}_{2}$ and decreased $\mathrm{CO}_{2}$ for this series. But while the $\mathrm{CO}_{2}$ was less than expected, the TC was itself less than for the previous series. Again, the formation of the black substance in the dry pipette in the presence of oxygen might indicate the formation of an oxygen compound, and the $\mathrm{O}_{2}$ consumed might indicate this. While these effects are of a second order of magnitude, they are nonetheless interesting.

The nitrogen balance for this series shows an average gain of $0.04 \mathrm{ml}$. This and the value for $\mathrm{CO}$ computed from $\mathrm{TC}+\mathrm{CO}_{2}$ suggest an incomplete combustion in the dry state, but we were unable to demonstrate this experimentally.

At this time it will be well to review the nitrogen balance for each of the four series of analyses already discussed. To complete the picture, the data from series 5 will be anticipated. The average nitrogen lost or gained during each series was as follows:

\begin{tabular}{|c|c|}
\hline Series & $m l$ \\
1 & +0.01 \\
2 & +.04 \\
3 & -.01 \\
4 & +.04 \\
5 & -.01 \\
\hline
\end{tabular}

While the amounts involved are small, the gains for series 2 and 4 are somewhat out of line. The most likely explanation for this is slightly involved, but brings out an important fact concerning the oxygen consumed during combustion. The whole picture becomes clear by correlating the following separate facts:

1. Oxygen is determined by absorption in a solution of alkaline pyrogallol. It is known from experimental work that the particular solution of pyrogallol used in this work yields no significant amount 
of carbon monoxide during reaction with oxygen, provided the proportion of the oxygen is 0.2 of the whole or less, and the reaction is conducted so that little or no expended pyrogallol remains in contact with unabsorbed oxygen [9]. However, if the partial pressure of the oxygen is high, small but measurable amounts of carbon monoxide may be generated. Any carbon monoxide so produced will appear in the residue, after absorption, as so much nitrogen, and the oxygen determined will be correspondingly too low.

2. During series 1 and 3, the diluting nitrogen used with each analysis was stored over the solution of potassium hydroxide, so that it mixed with the residual gas after absorption of the carbon dioxide and before the absorption of oxygen. This lowered the partial pressure of oxygen in the gas entering the pyrogallol solution. During series 5 a like condition prevailed, since air, instead of commercial oxygen, was used for combustion in this series only. But during series 2 and 4, through an oversight, the diluting nitrogen was stored over the pyrogallol, thus making the partial pressure of oxygen in the gas originally entering this solution higher than existed during the other series. Under these circumstances, negligible amounts of carbon monoxide would be expected from the reaction of oxygen with pyrogallol in series 1,3 , and 5 ; but this would not be true for series 2 and 4. The data indicate that on the average about $0.04 \mathrm{ml}$ of $\mathrm{CO}$ was generated during the absorption of excess oxygen in series 2 and 4, and that this carbon monoxide appeared as a gain in nitrogen.

3 . This explanation of the nitrogen gained is consistent with determinations of carbon monoxide generated during the analysis of the commercial oxygen used for combustion during series 1 to 4 , inclusive. This carbon monoxide was determined by the iodine pentoxide method and by combustion of concentrated residues from absorptions of many samples of oxygen.

While the above discussion rounds out the picture with respect to the nitrogen balance, futher consideration should be given to the small amounts of carbon monoxide sometimes generated when oxygen reacts with pyrogallol, since the measurement of oxygen consumed during the combustion will also be affected.

In general, the oxygen consumed during combustion is found by determining the excess oxygen in the products of combustion and subtracting this excess from the measured amount of oxygen originally taken. Thus the composition of the oxygen taken for combustion must be known. If air is not taken, usually commercial oxygen separated from air by rectification is used. This oxygen contains nitrogen as an impurity. Its composition is ordinarily determined by the same method used during an analysis to determine the excess oxygen in the products of combustion, that is, by absorption in alkaline pyrogallol. Since the apparent oxygen determined by this method depends upon the partial pressure of oxygen in the gas entering the pyrogallol solution, it is obvious that the determination of excess oxygen in the products of combustion may not strictly compare with the determination of oxygen in the commercial "oxygen" taken for this combustion. In other words, different amounts of carbon monoxide may be generated during these two separate but interdependent determinations. For this reason, accurate work requires the determination of generated carbon monoxide in both cases, or else 
the adjustment of the partial pressures of oxygen so that they will be nearly equal during both determinations.

In the work here reported, the commercial oxygen was analyzed by absorption in pyrogallol with subsequent determination of and correction for generated carbon monoxide. In addition, analysis was made by combustion with pure hydrogen. The composition of the commercial oxygen was accordingly well established. The original analytical procedure would bave eliminated significant error caused by the generation of carbon monoxide during the absorption of oxygen in the products of combustion, simply by diluting the oxygen with a sufficient amount of nitrogen. Therefore, no determination of generated carbon monoxide was made, although the failure to observe the outlined procedure in series 2 and 4 made such a determination desirable.

\section{SERIES 5}

(No water; no rubber connections; air used for the combustion instead of oxygen)

This series of analyses made use of the nearest approach to a standard gas mixture that is ordinarily available to the gas analyst-dry, $\mathrm{CO}_{2}$-free air. The advantages gained are a definite knowledge of the amount of oxygen introduced for the combustion, a supply of diluent nitrogen without its preparation and separate measurement, and a reduction in the partial pressure of $\mathrm{CO}_{2}$ in the products of combustion. The disadvantage is the limitation of the amount of sample which can be used, and consequently of the three measurements $\mathrm{TC}, \mathrm{CO}_{2}$, and $\mathrm{O}_{2}$.

In spite of this limitation imposed on percentage volumetric accuracy, the results are pleasing with respect to $\mathrm{TC}$ and $\mathrm{CO}_{2}$, both of which approached a bit nearer to the 100-percent axis which represents the known fact. The average of the oxygen values leaves nothing to be desired, but the reproducibility of these values is not so good. The nitrogen balance is satisfactory $(-0.01 \mathrm{ml})$. This procedure has much to commend it.

\section{CORRECTION OF ANALYTICAL DATA FOR KNOWN ERRORS}

Now that the analytical data have been presented, the accuracy and reproducibility of this determination made under the five sets of conditions noted are both disclosed, and the analyst and the user of his data may know about what to expect when dealing with this gas so determined. From the practical viewpoint, the analyses of series 1 offer a measure of the order of magnitude of the accuracy which may have been achieved in laboratories using modern apparatus with reasonable care, and conducting determinations in such a manner that the partial pressures of the various gases at each step of the analysis would approximate those main tained in this work.

In addition to offering this useful information, it will be well, as always, to see if something further can be done to improve these results by correcting them for known errors. If the analytical results can thus be brought into closer agreement with the known purity of the $\mathrm{CO}$, the remedial measures thus indicated will be worth the using.

Assuming that the chemistry involved is above reproach, the two distinct types of error then to be expected are deviations from the ideal 
gas laws, and the solution of the gases in water and rubber. These have been previously discussed [7], and data may be drawn from past experiments to make the necessary corrections involved. In addition, fresh data are offered to give, at least roughly, the order of magnitude of the deviations from ideality of the various mixtures existing during the analysis. Since these last results may be at variance with theoretical values for these deviations, the data will first be corrected for errors arising from solution in water and rubber, and then be corrected for deviations from ideality on the basis of both theoretical and approximately measured values.

In making these corrections, it will be simpler to deal in the units actually observed in the analysis-namely, milliliters of gas measured at atmospheric pressure and laboratory temperature (average $25^{\circ} \mathrm{C}$ ). This method has the additional virtue of telling the analyst just where he stands with respect to the factor which fundamentally limits his work-volumetric accuracy. It will be seen that application of the corrections for solution of $\mathrm{CO}_{2}$ brings the results of the five series into better agreement among themselves, and that application of appropriate corrections for deviations from the ideal gas laws brings the results into better agreement with the known facts regarding the purity of the CO.

\section{CORRECTIONS FOR LOSS OF $\mathrm{CO}_{2}$ BY SOLUTION}

Corrections for solution of $\mathrm{CO}_{2}$ in $\mathrm{H}_{2} \mathrm{O}$ may be made for series 1, 2, and 3 on the basis that the solubility is $0.8 \mathrm{ml}$ of $\mathrm{CO}_{2}$ per ml of $\mathrm{H}_{2} \mathrm{O}$ (at $26^{\circ} \mathrm{C}$ ) when the pressure of $\mathrm{CO}_{2}$ in the gas phase is 1 atmosphere. Under the conditions of the experiments in series 1,2 , and 3 , in which the partial pressure of $\mathrm{CO}_{2}$ is 0.66 atmosphere, this reduces to $0.53 \mathrm{ml}$ of $\mathrm{CO}_{2}$ per ml of $\mathrm{H}_{2} \mathrm{O}$. Correction for solution of $\mathrm{CO}_{2}$ in rubber may be made for series 1 on the basis that $0.05 \mathrm{ml}$ of $\mathrm{CO}_{2}$ would be lost by this process [8] during the time of an analysis if the $\mathrm{CO}_{2}$ were at atmospheric pressure. This corresponds to a loss of $0.03 \mathrm{ml}$ of $\mathrm{CO}_{2}$ per analysis at the partial pressure of the $\mathrm{CO}_{2}$ in these experiments.

The observed average equations for the series, expressed in milliliters, and referred to a fixed sample of $60 \mathrm{ml}$ of $\mathrm{CO}$, are:

Series 1. $60 \mathrm{CO}+30.03 \pm 0.06 \mathrm{O}_{2} \rightarrow 59.59 \pm 0.05 \mathrm{CO}_{2}+30.41 \pm 0.04 \mathrm{TC}$

2. $60 \mathrm{CO}+30.05 \pm 0.07 \mathrm{O}_{2} \rightarrow 59.48 \pm 0.05 \mathrm{CO}_{2}+30.52 \pm 0.02 \mathrm{TC}$

3. $60 \mathrm{CO}+30.01 \pm 0.04 \mathrm{O}_{2} \rightarrow 59.69 \pm 0.04 \mathrm{CO}_{2}+30.33 \pm 0.03 \mathrm{TC}$

4. $60 \mathrm{CO}+30.04 \pm 0.05 \mathrm{O}_{2} \rightarrow 59.69 \pm 0.03 \mathrm{CO}_{2}+30.28 \pm 0.02 \mathrm{TC}$

5. $60 \mathrm{CO}+30.00 \pm 0.06 \mathrm{O}_{2} \rightarrow 59.76 \pm 0.03 \mathrm{CO}_{2}+30.26 \pm 0.03 \mathrm{TC}$

These equations corrected for solubility of $\mathrm{CO}_{2}$ in water and rubber are:

$$
\begin{array}{rll}
\text { Series } 1 . & 60 \mathrm{CO}+30.03 \mathrm{O}_{2} \rightarrow 59.67 \mathrm{CO}_{2}+30.33 \mathrm{TC} \\
\text { 2. } & 60 \mathrm{CO}+30.05 \mathrm{O}_{2} \rightarrow 59.74 \mathrm{CO}_{2}+30.26 \mathrm{TC} \\
\text { 3. } & 60 \mathrm{CO}+30.01 \mathrm{O}_{2} \rightarrow 59.74 \mathrm{CO}_{2}+30.28 \mathrm{TC} \\
\text { 4. } & 60 \mathrm{CO}+30.04 \mathrm{O}_{2} \rightarrow 59.69 \mathrm{CO}_{2}+30.28 \mathrm{TC} \\
\text { 5. } & 60 \mathrm{CO}+30.00 \mathrm{O}_{2} \rightarrow 59.76 \mathrm{CO}_{2}+30.26 \mathrm{TC}
\end{array}
$$

The average equation for all five series corrected for solubility is

$$
60 \mathrm{CO}+30.03 \mathrm{O}_{2} \rightarrow 59.72 \mathrm{CO}_{2}+30.28 \mathrm{TC} \text {. }
$$


The deviations of each series from this average are:

$\begin{array}{rlll}\text { Series 1. } & 0.00 & \mathrm{O}_{2} \rightarrow 0.05 & \mathrm{CO}_{2}+0.05 \mathrm{TC} \\ \text { 2. } & 0.02 & \mathrm{O}_{2} \rightarrow 0.02 & \mathrm{CO}_{2}+0.02 \mathrm{TC} \\ \text { 3. } & 0.02 & \mathrm{O}_{2} \rightarrow 0.02 & \mathrm{CO}_{2}+0.00 \mathrm{TC} \\ \text { 4. } & 0.01 & \mathrm{O}_{2} \rightarrow 0.03 & \mathrm{CO}_{2}+0.00 \mathrm{TC} \\ \text { 5. } & 0.03 & \mathrm{O}_{2} \rightarrow 0.04 & \mathrm{CO}_{2}+0.02 \mathrm{TC}\end{array}$

The improved agreement is at once noted. $\mathrm{CO}_{2}$ and $\mathrm{TC}$ for series 5 are somewhat out of line, but it will be remembered that the partial pressure of $\mathrm{CO}_{2}$ in the products of combustion was only 0.31 for this series as against 0.66 for the other series, and correction for deviation from ideality may still remedy this.

\section{CORRECTIONS FOR DEVIATION FROM IDEALITY}

The next corrections in order are those dealing with deviations from the ideal gas laws. The two mixtures which will exhibit the greatest deviations during these analyses are (expressed in partial pressures) $0.66 \mathrm{CO}_{2}+0.34\left[\mathrm{O}_{2}+\mathrm{N}_{2}\right]$ (series 1 to 4 , inclusive) and $0.31 \mathrm{CO}_{2}+0.69$ $\left[\mathrm{O}_{2}+\mathrm{N}_{2}\right]$ (series 5).

Dry $\mathrm{CO}_{2}$ and dry air were measured separately, and were mixed in such proportions that the above partial pressures were obtained. To check the measurements, two volumes of dry air were measured in like amounts. The averages of 10 such determinations of each are as follows:

1. When $60 \mathrm{ml}$ of dry $\mathrm{CO}_{2}$ was mixed with $30.9 \mathrm{ml}$ of dry air, the observed expansion was $0.04 \mathrm{ml} \pm 0.01$.

2. When $60 \mathrm{ml}$ of dry air was mixed with $27 \mathrm{ml}$ of dry $\mathrm{CO}_{2}$, the observed expansion was 0.056 , corresponding to $0.11 \pm 0.02$ had the sample been $60 \mathrm{ml}$ of $\mathrm{CO}$ instead of the $30 \mathrm{ml}$ necessarily used.

3 . When $60 \mathrm{ml}$ of air was mixed with $30 \mathrm{ml}$ of air, there was no observed expansion within $\pm 0.01 \mathrm{ml}$.

The TC measured during the analyses will therefore be less by amounts corresponding to these expansions, and the $\mathrm{CO}_{2}$ correspondingly greater, than if the gases had been measured separately. If we correct the equations which have already been corrected for solution of $\mathrm{CO}_{2}$, the results are:

Series 1. $60 \mathrm{CO}+30.03 \pm 0.06 \mathrm{O}_{2} \rightarrow 59.63 \pm 0.05 \mathrm{CO}_{2}+30.37 \pm 0.04 \mathrm{TC}$

2. $60 \mathrm{CO}+30.05 \pm 0.07 \mathrm{O}_{2} \rightarrow 59.70 \pm 0.05 \mathrm{CO}_{2}+30.30 \pm 0.02 \mathrm{TC}$

3. $60 \mathrm{CO}+30.01 \pm 0.04 \mathrm{O}_{2} \rightarrow 59.70 \pm 0.04 \mathrm{CO}_{2}+30.32 \pm 0.03 \mathrm{TC}$

4. $60 \mathrm{CO}+30.04 \pm 0.05 \mathrm{O}_{2} \rightarrow 59.65 \pm 0.03 \mathrm{CO}_{2}+30.32 \pm 0.02 \mathrm{TC}$

5. $60 \mathrm{CO}+30.00 \pm 0.06 \mathrm{O}_{2} \rightarrow 59.65 \pm 0.03 \mathrm{CO}_{2}+30.37 \pm 0.03 \mathrm{TC}$

The average equation for all five of the series, taken from the above separate corrected equations, is

$$
60 \mathrm{ml} \mathrm{CO}+30.03 \mathrm{ml} \mathrm{O}_{2} \rightarrow 59.67 \mathrm{ml} \mathrm{CO}+30.34 \mathrm{ml} \mathrm{TC}
$$

The deviations of each series from this equation are:

$$
\begin{array}{rlll}
\text { Series 1. } & 0.00 \mathrm{O}_{2} \rightarrow 0.04 \mathrm{CO}_{2}+0.03 \mathrm{O}_{2} \\
2 . & 0.02 \mathrm{O}_{2} \rightarrow 0.03 \mathrm{CO}_{2}+0.04 \mathrm{O}_{2} \\
\text { 3. } & 0.02 \mathrm{O}_{2} \rightarrow 0.03 \mathrm{CO}_{2}+0.02 \mathrm{O}_{2} \\
\text { 4. } & 0.01 \mathrm{O}_{2} \rightarrow 0.02 \mathrm{CO}_{2}+0.02 \mathrm{O}_{2} \\
5 . & 0.03 \mathrm{O}_{2} \rightarrow 0.02 \mathrm{CO}_{2}+0.03 \mathrm{O}_{2}
\end{array}
$$

This now brings the $\mathrm{CO}_{2}$ and TC of series 5 in line with those of the other series. The differences may not represent real effects, since all of the data are now within the reproducibility of measurement. 
Had the physical and chemical behavior of the analysis been perfect in all respects, the ideal stoichiometric relationship

$$
60 \mathrm{CO}+30 \mathrm{O}_{2} \rightarrow 60 \mathrm{CO}_{2}+30 \mathrm{TC}
$$

would have prevailed. This ideal relationship itself must be corrected for deviation of the gases from ideality, and this may be done according to values kindly supplied by C. S. Cragoe, of this Bureau. The values were calculated by Cragoe from the best available data for the average conditions prevailing during these analyses. They are believed to be good to 1 in the fourth place. The corrected equation may be written

$$
\text { (60) (0.9997) } \mathrm{CO}+30(0.9994) \mathrm{O}_{2} \rightarrow 60(0.9949) \mathrm{CO}_{2}
$$

This corresponds to

$$
60 \mathrm{CO}+29.99 \mathrm{O}_{2} \rightarrow 59.71 \mathrm{CO}_{2}+30.28 \mathrm{TC}
$$

The deviations of these values from the observed values corrected for solution of $\mathrm{CO}_{2}$ are

$$
\text { Series } \begin{array}{rrrr}
1 . & -0.04 \mathrm{O}_{2} \rightarrow+0.04 \mathrm{CO}_{2}+-0.05 \mathrm{TC} \\
2 . & -0.06 \mathrm{O}_{2} \rightarrow+0.03 \mathrm{CO}_{2}-0.02 \mathrm{TC} \\
3 . & -0.02 \mathrm{O}_{2} \rightarrow-0.03 \mathrm{CO}_{2} 0.00 \mathrm{TC} \\
4 . & +0.03 \mathrm{O}_{2} \rightarrow+0.02 \mathrm{CO}_{2} 0.00 \mathrm{TC} \\
5 . & -0.01 \mathrm{O}_{2} \rightarrow-0.05 \mathrm{CO}_{2}+0.02 \mathrm{TC}
\end{array}
$$

This agreement is satisfactory for nearly every measurement made during the five series of analyses, and gratifyingly so for the group taken as a whole. Compare the ideal stoichiometric relationship corrected for deviation from ideality:

$$
60 \mathrm{CO}+29.99 \mathrm{O}_{2} \rightarrow 59.71 \mathrm{CO}_{2}+30.28 \mathrm{TC} \text {; }
$$

with the average measurements for all five series corrected for errors of solubility,

$$
60 \mathrm{CO}+30.03 \mathrm{O}_{2} \rightarrow 59.72 \mathrm{CO}_{2}+30.28 \mathrm{TC}
$$

The deviation is only

$$
0.04 \mathrm{O}_{2} \rightarrow 0.01 \mathrm{CO}_{2}+0.00 \text { TC. }
$$

These values represent milliliters. If the individual analyses were just that good, the analyst would be saved much effort.

Expressed in the ordinary fashion, the observed average values corrected for known solubility and deviation from ideality give the stoichiometric equation

$$
2 \mathrm{CO}+1.001_{0} \mathrm{O}_{2} \rightarrow 2.000_{0} \mathrm{CO}_{2}+1.000_{3} \mathrm{TC}
$$

If we assume that $0.04 \mathrm{ml}$ of $\mathrm{CO}$ was generated during the absorption of excess oxygen in series 2 and 4, as previously indicated, the above equation may be corrected, and will then give the relationship

$$
2 \mathrm{CO}+1.000_{1} \mathrm{O}_{2} \rightarrow 2.000_{0} \mathrm{CO}+1.000_{3} \mathrm{TC} \text {. }
$$


A second stoichiometric relationship can be set up for series 1 to 4 , inclusive, and a third for series 5, by assuming that the deviation of $\mathrm{CO}_{2}$ is proportional to its partial pressure. This is by no means necessarily true [10], but the computation can be made for the sake of general interest, since it is often resorted to in so-called exact gas analysis. The equation for series 1 to 4 becomes

$$
\text { (60) (0.9997) } \mathrm{CO}+30(0.9994) \mathrm{O}_{2} \rightarrow 60(0.9963) \mathrm{CO}_{2} \text {, }
$$

which reduces to

$$
60 \mathrm{CO}+29.99 \quad \mathrm{O}_{2} \rightarrow 59.80 \quad \mathrm{CO}_{2}+30.19 \mathrm{TC} ;
$$

and that for series 5 becomes

$$
\text { (60) (0.9997) } \mathrm{CO}+30(0.9994) \mathrm{O}_{2} \rightarrow 60(0.9984) \mathrm{CO}_{2} \text {, }
$$

which reduces to

$$
60 \mathrm{CO}+29.99 \mathrm{O}_{2} \rightarrow 59.92 \mathrm{CO}_{2}+30.08 \mathrm{TC} \text {. }
$$

Equations 5 and 7 are out of line with the observed data corrected for solution of $\mathrm{CO}_{2}$. This method of calculation cannot be recommended in the present instance.

\section{COMPUTATION AS AN UNKNOWN}

So far the data have been treated on the basis of the known composition of the sample analyzed. Had this gas been submitted to the analyst as an unknown-and this represents the usual case-the data would have been computed on the assumption that other combustibles were present. It will be interesting to see what the resulting report would have been.

The data for the first series will be selected, since this more nearly represents average laboratory practice. Computed as though $\mathrm{H}_{2}$ and $\mathrm{CH}_{4}$ may have been present, according to the equation

$$
\begin{aligned}
\mathrm{H}_{2} & =\mathrm{TC}-\mathrm{O}_{2} \\
\mathrm{CH}_{4} & =\mathrm{O}_{2}-1 / 3\left(\mathrm{CO}_{2}+\mathrm{TC}\right) \\
\mathrm{CO} & =1 / 3\left(4 \mathrm{CO}_{2}+\mathrm{TC}-3 \mathrm{O}_{2}\right),
\end{aligned}
$$

the analysis would have been reported:

$$
\begin{gathered}
\mathrm{CO}, 99.3 \text { percent } \\
\mathrm{H}_{2}, 0.6 \text { percent } \\
\mathrm{CH}_{4}, 0.03 \text { percent }
\end{gathered}
$$

Had the data been corrected for solubility of $\mathrm{CO}_{2}$ in water and rubber, the analysis would have been reported

$$
\begin{gathered}
\mathrm{CO}, 99.5 \text { percent } \\
\mathrm{H}_{2} \text {, negative } \\
\mathrm{CH}_{4}, 0.04 \text { percent }
\end{gathered}
$$

Thus a sample of reasonably pure carbon monoxide would never be certified as such by the customary volumetric analysis. 


\section{REFERENCES}

[1] J. R. Branham and E. O. Sperling, Bubbler tip of Pyrex glass for difficult absorptions, J. Research NBS 22, 701 (1939) RP1214.

[2] Martin Shepherd, Analytical separation and purification of gases by fractional distillation and rectification at low temperatures, J. Research NBS 26, 227 (1941) RP1372.

[3] Martin Shepherd, A critical test for the purity of gases, BS J. Research 12, 184 (1934) RP643.

[4] Martin Shepherd, An improved apparatus and method for the analysis of gas mixtures by combustion and absorption, BS J. Research 6, 121 (1931) RP226.

[5] J. R. Branham and Martin Shepherd, A gasometric method and apparatus for the analysis of mixtures of ethylene oxide and carbon dioxide, J. Research NBS 22, 171 (1939) RP1175.

[6] J. R. Branham and Max Sucher, Displacement of nitrogen from and its solution in certain reagents during volumetric gas analysis, J. Research NBS 21, 63 (1938) RP1113.

[7] Martin Shepherd and J. R. Branham, Critical study of the determination of ethane by combustion over platinum in the presence of excess oxygen, BS J. Research 11, 783 (1933) RP625.

[8] See [7] and J. R. Branham, Errors in gas analysis arising from loss of gas by solution in rubber connections and stopcock lubricant, BS J. Research 12, 353 (1934) RP661.

[9] Much of this has not been reported, but previous mention of the behavior of the reagent is made in RP266 and in "The composition of the atmosphere at approximately 21.5 kilometers," by Martin Shepherd. The National Geographic Society and U. S. Army Air Corps Stratosphere Flight of 1935 in Balloon Explorer $I I$, p. 117.

[10] This subject has been discussed previously [5, 7].

WAshington, March 21, 1941 